\title{
Capitais intangíveis e desenvolvimento regional
}

Paulo R. Haddad

\begin{abstract}
Resumo: O processo de desenvolvimento sustentável de uma região depende não só do seu crescimento econômico, mas principalmente da sua capacidade de organização social e política, a qual está relacionada com a disponibilidade de diferentes formas de capitais intangíveis na região. De fato, a promoção do desenvolvimento regional deve estar fundamentalmente baseada na formulação e na implementação de políticas, programas e projetos concebidos e implantados a partir da atuação das sociedades locais, cabendo às agências e instituições dos governos federal e estadual o papel de parceiras nesse processo. Uma forma de ilustrar como os capitais intangíveis podem contribuir para o desenvolvimento regional é por meio dos Arranjos Produtivos Locais (APLS) no Brasil, particularmente através do equilíbrio entre a oferta e a demanda de serviços de inovação. Nesse sentido, este artigo objetiva analisar a importância dos capitais intangíveis para o processo de desenvolvimento regional, sendo os APLs utilizados aqui como exemplos significativos.
\end{abstract}

Palavras-chave: capitais intangíveis; desenvolvimento regional; crescimento econômico; educação superior; desenvolvimento endógeno.

\section{Intangible capitals and regional development}

\begin{abstract}
The sustainable development of a region depends not only on its economic growth, but principally on its capacity for social and political organization, which is related to the availability of different forms of intangible capitals in the region. In fact, the promotion of regional development should be essentially based on the formulation and implementation of politics, programs and projects designed and implemented from the action of local societies. In this process, the agencies and institutions of the federal and state governments play the role of partners. One way of illustrating how the intangible capitals can contribute to regional development is by means of the Local Productive Arrangements (APLs) in Brazil, particularly through the balance between supply and demand of innovation services. In this regard, this paper aims at analysing the importance of intangible capitals for the process of regional development, being the APLs used here as a very illustrative example.
\end{abstract}

Keywords: intangible capitals; regional development; economic growth; higher education; endogenous development.

JEL: R 10

${ }^{1}$ Professor-emérito da UFMG, professor do IBMEC, ex-Ministro da Fazenda e do Planejamento. 


\section{Introdução}

As preocupações com o desenvolvimento regional remontam à Alemanha do século XIX e estavam centradas na localização das atividades produtivas. De fato, a teoria da localização foi dominante até o fim da II Guerra Mundial, ganhando o desenvolvimento regional um novo impulso após este período em função dos desafios que muitos economistas tiveram para explicar as desigualdades geradas pelo processo de desenvolvimento econômico. A consequência imediata foi a formulação e a implementação de políticas públicas voltadas para a promoção do desenvolvimento regional com vistas à superação do atraso econômico. Estas políticas, comandadas principalmente pelo governo federal, geravam condições externas às decisões locais que podiam impulsionar ou mesmo estancar o crescimento econômico. Elas foram, quase sempre, predominantes e capazes de explicar o crescimento econômico e a evolução da renda de uma determinada região, particularmente das regiões periféricas não-desenvolvidas.

Entretanto, a partir dos anos 60 teve início um progressivo desencantamento com as políticas de desenvolvimento regional implementadas, uma vez que os seus resultados sociais foram, em geral, desalentadores. Na realidade, o processo de desenvolvimento sustentável de uma região depende não só do seu crescimento econômico, mas principalmente da sua capacidade de organização social e política, a qual está relacionada ao aumento da autonomia local para a tomada de decisões, ao aumento da capacidade para reter e reinvestir o excedente econômico gerado pelo processo de crescimento local, a um crescente processo de inclusão social, a um processo permanente de conservação e preservação do ecossistema regional. Esta capacidade de organização social da região é o fator endógeno por excelência para transformar o crescimento em desenvolvimento, através de uma complexa malha de instituições e de agentes de desenvolvimento, articulados por uma cultura regional e por um projeto político local (Boisier 1992). De fato, a promoção do desenvolvimento regional deve estar fundamentalmente baseada na formulação e na implementação de políticas, programas e projetos concebidos e implantados a partir da atuação das sociedades locais, cabendo às agências e instituições dos governos federal e estadual o papel de parceiras nesse processo.

As novas concepções que buscam explicar a razão pela qual alguns países e regiões crescem e se desenvolvem mais rapidamente do que os demais, ressaltam o conhecimento como um fator de produção separado e a importância de investimentos na criação do conhecimento e nas atividades de Pesquisa e Desenvolvimento (P\&D). O capital humano e as habilidades de um país ou região determinam o seu crescimento econômico no longo prazo e suas chances de transformar este crescimento em processos de desenvolvimento. Como as empresas tendem a subinvestir em P\&D, onde os resultados são apenas parcialmente capturados e apropriados por elas, os governos nacionais e regionais deveriam tomar medidas apropriadas para superar esta falha de 
mercado. Uma forma de ilustrar como a informação e o conhecimento, acumulados nas instituições de ensino superior, podem contribuir dinamicamente para o desenvolvimento regional, se apresenta nos processos de promoção de arranjos produtivos locais (APLs) no Brasil, particularmente através do equilíbrio entre a oferta e a demanda de serviços de inovação. Neste sentido, este artigo objetiva analisar a importância dos capitais intangíveis para o processo de desenvolvimento regional, sendo os APLs utilizados aqui como exemplos significativos.

\section{Crescimento e desenvolvimento das regiões}

A localização e a implantação de novas atividades econômicas de maior escala numa região podem elevar os seus níveis de produção, de renda, de emprego e da base tributável a um ritmo mais intenso do que o crescimento de sua população, sem que, entretanto, se configure um processo de desenvolvimento. Os valores per capita do produto e da renda, assim como os indicadores de emprego, se expandem, denotando, basicamente, que a região estará vivendo uma etapa favorável na sua trajetória de crescimento econômico, e que, em média, estará havendo um aumento na quantidade de bens e serviços à disposição dos seus habitantes. Se as taxas de crescimento do PIB e da renda per capita da região se mantiverem positivas e elevadas por um longo período, pode-se afirmar que foi encontrada uma alternativa de expansão sustentada da sua economia.

Este processo de crescimento econômico irá depender, principalmente, da capacidade da região para negociar e atrair recursos (financeiros, tecnológicos, institucionais, etc.) nacionais e internacionais, públicos e privados, através de diferentes modalidades (promoção de projetos de investimentos; transferências intergovernamentais de natureza constitucional e não-constitucional; etc.). Dependerá, também, dos impactos que as políticas macroeconômicas (monetária, cambial, fiscal) e setoriais (transporte, energia, etc.) terão sobre a economia local. Estas políticas, comandadas principalmente pelo Governo Federal, geram condições externas às decisões locais que podem ou estimular ou frear o crescimento econômico, de acordo com os rebatimentos específicos destas políticas sobre a estrutura produtiva da região. Quase sempre, estas políticas são, por si só, predominantes e capazes de explicar o crescimento econômico e a evolução da renda de uma determinada região, particularmente de regiões periféricas não-desenvolvidas.

Por outro lado, o processo de desenvolvimento sustentável de uma região, que pressupõe o seu crescimento econômico, dependerá, fundamentalmente, da sua capacidade de organização social e política, que se associa ao aumento da autonomia local para a tomada de decisões, ao aumento da capacidade para reter e reinvestir o excedente econômico gerado pelo processo de crescimento 
local, a um crescente processo de inclusão social, a um processo permanente de conservação e preservação do ecossistema regional. Esta capacidade de organização social da região é o fator endógeno por excelência para transformar o crescimento em desenvolvimento, através de uma complexa malha de instituições e de agentes de desenvolvimento, articulados por uma cultura regional e por um projeto político local (Boisier 1992).

Enfim, segundo esta concepção, o desenvolvimento sustentável de uma determinada região pressupõe:

- um crescente processo de autonomia decisória;

- umico crescente capacidade de captação e reinversão do excedente econômico;

- um crescente processo de inclusão social (inclusive digital);

- uma crescente consciência e ação ambientalista;

- uma crescente sincronia intersetorial e territorial do crescimento;

- uma crescente percepção coletiva de pertencer à região.

Uma concepção adequada de desenvolvimento da região deve conter, como elemento essencial, um crescente processo de inclusão social. Esta preocupação deriva do fato de que a análise das experiências de expansão de diferentes economias nacionais e regionais, no Pós-guerra, não revela a existência de nenhuma correlação geral e sistemática entre o processo de crescimento econômico e a distribuição de renda e da riqueza geradas neste processo. Concretamente, mostra que:

- A desigualdade não aumenta numa primeira fase do processo de crescimento econômico para depois atenuar; existem quase tantos países e regiões em desenvolvimento em que a desigualdade aumenta, como países e regiões em que esta diminui, nesta primeira fase;

- A desigualdade não tende a se tornar mais aguda nos países e regiões em desenvolvimento mais pobres, do que nos menos pobres;

- A desigualdade não tende a se tornar mais aguda, quanto mais rápido seja o crescimento econômico;

- Uma desigualdade maior inicialmente não induz a um crescimento maior posteriormente;

- Crescimento e equidade podem ser objetivos conflitivos, como podem chegar a ser complementares ou independentes; a relação dependerá das políticas que se adotem. As maiores possibilidades de conflito podem ocorrer entre aquelas políticas em que ambos objetivos são complementares no longo prazo, ainda que aparentemente contrários no curto prazo, como por exemplo: a maioria das políticas de sustentabilidade ambiental ou das políticas de inversões em capital humano com longos períodos de gestação (Cepal 1992; MMA 2002; Rocha 2003; Schwartzman 2004).

Neste sentido, constatou-se, em diversos países e regiões, que a compatibilidade entre o crescimento econômico e o desenvolvimento social não se processa espontaneamente. Da aplicação das estratégias que se firmaram no pressuposto de que os objetivos redistributivos e de eqüidade ficassem su- 
bordinados à manutenção do crescimento acelerado do PIB, concluiu-se que a redução das desigualdades não foi atingida através de impactos indiretos gerados pela prioridade atribuída aos critérios de eficiência. Admitiu-se, em princípio, que se expandindo o produto e a base tributável da economia seria mais fácil para o poder público manipular maiores recursos, capazes de favorecer soluções para os problemas econômicos e sociais dos segmentos mais pobres da população; vale dizer, acreditava-se que o desenvolvimento social seria um subproduto cronológico do crescimento econômico.

Contudo, a experiência histórica vem demonstrando que a simples mobilização intensiva dos fatores de produção tende a reproduzir, agora sim, de forma espontânea, as condições sociais iniciais que lhe deram sustentação. Assim, o poder indutor do crescimento econômico propicia maior diferenciação dos sistemas sociais sem, contudo, gerar mais eqüidade, pois esta não é impulsionada por nenhum mecanismo auto-sustentado, porquanto os efeitos genuínos do crescimento econômico estão estruturalmente vinculados aos imperativos da acumulação e à lógica da diferenciação social (Rocha 2006)².

A Agenda 21 Brasileira, apresentada na reunião de Johanesburgo em 2002, admite que uma concepção ampliada de desenvolvimento sustentável, a qual inclui a eqüidade social, pode conter uma justificativa instrumental para a redução da pobreza como uma forma para proteger o meio ambiente: como as famílias pobres (ao mesmo tempo, vítimas e agentes de danos ambientais) quase sempre não dispõem de recursos para evitar a degradação dos recursos ambientais como valor de uso, a redução da pobreza se apresenta como um pré-requisito para a conservação ambiental. Entretanto, o desenvolvimento humano em bases sustentáveis é um objetivo por si só, uma vez que intensifica diretamente a capacidade das pessoas para desfrutar uma vida longa e saudável, de tal forma que há ganhos imediatos no que é importante em última instância, enquanto se salvaguardam oportunidades no futuro.

É fundamental esclarecer, também, o indispensável papel do Estado na construção do processo de desenvolvimento sustentável no Brasil. A obrigação social de sustentabilidade, como têm insistido Amartya Sen (2000) e Anand e Sen (1996), não pode ser deixada inteiramente por conta do mercado, uma vez que o futuro não está adequadamente representado no mercado - pelo menos o futuro mais distante. O Estado deve servir como gestor dos interesses das futuras gerações, por meio de políticas públicas que utilizem mecanismos regulatórios ou de mercado, adaptando a estrutura de incentivos a fim de proteger o meio ambiente global e a base de recursos para as pessoas que ainda vão nascer.

${ }^{2}$ Uma ilustração do argumento é a Macrorregião Nordeste. Após quase meio século de políticas públicas, desde a criação da SUDENE em 1959, esta região conseguiu crescer, durante longos períodos, acima do crescimento médio brasileiro, sem contudo afetar significativamente as desigualdades sociais regionais. Os próprios indicadores de pobreza ainda são muito elevados: o Nordeste, em 2004, era responsável por $42 \%$ dos pobres brasileiros e $53 \%$ dos extremamente pobres ou indigentes, ou seja, a região tinha 24 milhões de pobres e 7 milhões de indigentes, em 2004. 
O conceito de necessidades é muito importante, pois tem de levar em consideração as carências dos mais pobres, assim como as limitações impostas pela situação atual da tecnologia e da organização social para atender às necessidades presentes e futuras. A noção de desenvolvimento sustentável não implica em deixar intacta a capacidade produtiva em todos os seus detalhes, mas conservar as oportunidades para que as futuras gerações disponham de condições de vida dignas. Para isto, é indispensável sinalizar a importância de que se formulem e se implementem políticas públicas adequadas de desenvolvimento sustentável, sem que se deixe a impressão da existência de um conflito ou de uma querela entre estas políticas e a lógica da economia de mercado.

Assim, não basta que se identifiquem oportunidades de investimentos na região e as formas de mobilizá-las (sistemas de promoção industrial), uma vez que a implantação e a operação destes investimentos podem resultar em processos socialmente excludentes para a população local e gerar apenas um ciclo restrito de crescimento econômico.

Em princípio, não se pode afirmar que os critérios de eficiência econômica e de eqüidade social (ou de distribuição de renda e de riqueza) que orientam a seleção e a prioridade de investimentos sejam mutuamente exclusivos. Um programa ou projeto de investimento, como o de melhoria da competitividade de um arranjo produtivo local de fruticultura, pode se enquadrar no critério de eficiência e no critério de distribuição, pois aumenta os fluxos de comercialização, as margens de lucro, e, enfim, a competitividade agrícola regional e, ao mesmo tempo, pode beneficiar os pequenos produtores de menor nível de rendimentos. O que interessa ressaltar é a ênfase dada ao programa ou projeto. Os programas ou projetos de natureza distributiva, por exemplo, devem, na maioria das vezes, ser eficientes sob o aspecto econômico. Contudo, o objetivo distributivista colocará todo o empenho, intencionalmente, nas ações e medidas que tenham maior probabilidade (ou que nos dão certeza) de beneficiar os grupos sociais de baixa renda na região.

Embora possam ocorrer programas ou projetos em determinada região com caráter fundamentalmente distributivo (e.g., programas de nutrição para grupos de baixa renda ou programas de transferência condicional de renda) e outros de caráter eminentemente de eficiência (e.g., criação de infraestrutura econômica para atuação de programas industriais num sistema de concorrência entre regiões), essa desvinculação é tanto mais obscura quanto mais longo for o período em que se avaliam os impactos dos programas e dos projetos (e.g., programas de educação para a população de baixa renda, os quais no longo prazo gerarão recursos humanos qualificados para o sistema produtivo).

As diferentes ações públicas e privadas de expansão econômica poderão afetar a distribuição da renda e da riqueza em suas áreas de atuação, através de benefícios derivados dos salários e dos rendimentos privados gerados 
pelas atividades produtivas e, também, dos benefícios dos projetos sociais não diretamente produtivos (por exemplo, educação e saúde). Na análise dos efeitos distributivos desses projetos não diretamente produtivos, é importante introduzir a dimensão temporal. À medida que a ênfase está na solução de problemas sociais pela alocação de fundos em programas diretamente ligados a esse setor, a estratégia é de curto prazo (políticas sociais de natureza compensatória). Quando se introduz a dimensão de longo prazo, a estratégia de desenvolvimento tem de considerar que o uso alternativo de fundos em projetos com efeitos distributivos positivos (a mobilização de arranjos produtivos locais em áreas de alto risco social) pode melhorar consideravelmente as carências existentes e vir a se constituir em solução mais adequada e com maior sustentabilidade. No longo prazo, eficiência e distribuição estão, quase sempre, bastante interligadas (Levy \& ViLLela 2006) 3 .

Enfim, o desenvolvimento social tem como fundamento uma concepção mais ampla de bem-estar de todos, que envolve o bem-estar físico, moral e espiritual, e não apenas a obtenção de algum bem ou serviço determinado. Esta concepção implica em que o planejamento tanto das políticas sociais quanto do portfólio de investimentos sociais tem que ser integrado, e não se constituir apenas em uma lista de decisões e de ações estratégicas, organizadas de maneira segmentada e parcial por diferentes especialistas.

O crescimento econômico é uma condição necessária, mas não suficiente para o desenvolvimento sustentável, o qual pressupõe um processo de inclusão social, com uma vasta gama de oportunidades e opções para as pessoas. Além de empregos de melhor qualidade e de rendas mais elevadas, é preciso que os brasileiros, todos os brasileiros, desfrutem de uma vida longa e saudável, adquiram conhecimentos técnicos e culturais, tenham acesso aos recursos necessários a um padrão de vida decente. Não pode haver desenvolvimento enquanto houver iniqüidades sociais crônicas no nosso País e em suas regiões. Assim, é indispensável que haja uma visão holística no processo de organização do portfólio de investimentos relativos ao desenvolvimento social e o seu equilíbrio com o portfólio de investimentos diretamente produtivos. Não se pode esperar que o desenvolvimento social seja um subproduto cronológico do crescimento econômico.

O conceito de desenvolvimento sustentável, além do mais, tem sua idéiaforça centrada na investigação científica das relações dos homens entre si e com a natureza. Dentro de modelos mais dinâmicos, onde a natureza deixa de participar apenas de forma passiva, de onde os homens retiram insumos necessários à produção das coisas úteis, para salientarem a dependência deste homem à natureza, à qual ele está materialmente condicionado. Baseia-se no

${ }^{3}$ É difícil imaginar programas compensatórios que sejam magnificentes e que vão se perpetuando ao longo do tempo. É o caso, por exemplo, do Bolsa-Família que já atinge mais de 11 milhões de famílias e mais de 40 milhões de brasileiros. Embora o seu custo fiscal não seja tão elevado quando comparado com outras despesas do OGU (os serviços da dívida mobiliária, por exemplo), há uma preocupação da sociedade brasileira para criar "portas de saída" para os seus beneficiários. 
imperativo moral de respeitar as necessidades das gerações futuras, o que implica a exigência de preservar o capital de estoque de recursos naturais, fundamental na organização das atividades econômicas. Vem tendo diferentes interpretações e abordagens, com ênfase ora na preservação dos seres vivos em geral, ora na preservação do homem e do seu habitat, mas sempre voltadas para a utilização não predatória dos recursos naturais e salvaguarda de oportunidades para as gerações futuras (MIN 1995; Pearce \& Turner 1991; Kolstad 2000).

Pearce e Turner (1991) propõem a seguinte definição operacional para o desenvolvimento sustentável do ponto de vista ambiental: este envolve a maximização dos benefícios líquidos do desenvolvimento econômico, sujeito à manutenção dos serviços e da qualidade dos recursos naturais ao longo do tempo. Esta manutenção implica, desde que seja possível, a aceitação das seguintes regras gerais:

- utilizar os recursos renováveis a taxas menores ou iguais à taxa natural que podem regenerar;

- otimizar a eficiênçia com que recursos não-renováveis são usados, sujeito ao grau de substituição entre recursos e progresso tecnológico;

- manter sempre os fluxos de resíduos no meio ambiente no nível igual ou abaixo de sua capacidade assimilativa.

As decisões sobre as formas de se utilizarem, sustentavelmente, os recursos naturais de uma região não podem ser tomadas sem que haja uma valoração econômica destes recursos, pois estes apresentam muitas opções alternativas para o desenvolvimento regional. Eles podem ser preservados; ou seja, nenhum uso humano é permitido na sua exploração. Eles podem ser conservados; ou seja, a ação antrópica pode ocorrer, desde que sejam mantidos os serviços e a qualidade dos recursos naturais ao longo do tempo. Assim, há um grande espectro de opções de conservação, principalmente quando se leva em consideração os demais objetivos de desenvolvimento de uma região (geração de emprego, redução da pobreza absoluta, etc.) e os respectivos trade-off, os quais se definem, economicamente, a partir de seus custos de oportunidade e benefícios sociais relativos. No fundo, o desafio é mostrar que os valores econômicos resultantes do uso sustentável dos recursos ambientais da região são superiores aos valores gerados pelas atuais formas de intervenção nas suas economias (Hadad \& Rezende 2002) ${ }^{4}$.

$\mathrm{O}$ uso econômico dos recursos ambientais pode colocar uma grave questão para as presentes e as futuras gerações, se não for conduzido segundo critérios de sustentabilidade. A compatibilidade entre crescimento econômico e sustentabilidade ambiental não ocorre como conseqüência natural do jogo es-

${ }^{4}$ Em geral, considera-se, como valor econômico total da natureza a soma do valor de uso direto (valor atribuído aos recursos naturais pelos indivíduos e pelas organizações que usufruem dos insumos e dos produtos do meio ambiente) mais o valor de uso indireto (ciclo de nutrientes, microclima, etc.) mais o valor de opção (conservação dos recursos ambientais para um uso futuro) mais o valor de existência (relacionado com as avaliações monetárias dos ativos ambientais). 
pontâneo de mercado. Na verdade, a livre mobilização dos fatores de produção pelos mecanismos de mercado, em geral, tem estimulado o uso predatório dos recursos ambientais em diversos contextos históricos. O próprio sistema de incentivos fiscais, adotado para a promoção do crescimento das áreas menos desenvolvidas do Brasil, não vinha incluindo até recentemente, entre os seus critérios de avaliação dos projetos de investimentos, a dimensão ambiental como variável relevante para a aprovação dos financiamentos. Assim, muitos projetos incentivados na Amazônia e no Centro-Oeste contribuíram para a devastação da flora e da fauna em extensas áreas de florestas tropicais e de cerrado (falhas de governo e não apenas falhas de mercado).

A Constituição Brasileira de 1988, ao buscar uma nova ordem institucional, a partir da década de noventa, destacou a questão da preservação ambiental como objetivo prioritário de desenvolvimento. Em 1995, foi editada uma lei extremamente rigorosa, um mecanismo institucional que dispõe sobre as sanções penais e administrativas derivadas de condutas e atividades lesivas ao meio ambiente. Esta lei contra os crimes ambientais leva, para o nível da decisão microeconômica (empresários e consumidores brasileiros), a questão dos custos ecológicos dos investimentos, da produção e do consumo público e privado.

Estes dispositivos legais, ancorados em intensa mobilização dos movimentos conservacionistas, nos dão certa garantia de que, ao longo do tempo, tenda a prevalecer, no Brasil, uma concepção alternativa de desenvolvimento na qual a questão ambiental não seja tratada à margem das principais decisões sobre a acumulação de capital e seus efeitos distributivos.

Como não tem sido de sucesso a história dos processos de implementação de leis e normas que tentam disciplinar os interesses individuais em função dos interesses coletivos, é fundamental trabalhar a consciência social de empresários e consumidores num comprometimento permanente com a dimensão do desenvolvimento sustentável em suas decisões cotidianas e estratégicas. Neste caso, as políticas ambientais deverão destacar a vinculação dos interesses individuais com o valor econômico da natureza de onde poderão extrair benefícios líquidos para a atual e as futuras gerações, desde que adotem processos tecnológicos e padrões de consumo ecologicamente corretos, segundo as diretrizes estratégicas e a plataforma de ação propostas pela Agenda 21 Brasileira.

Uma forma mais abrangente de se avaliarem as relações entre a economia e o meio ambiente é dada pelo conceito de capitalismo natural. Um elemento central do capitalismo natural é a idéia de que a economia moderna está passando de uma ênfase na produtividade humana para um aumento radical na produtividade dos recursos naturais (uma tonelada de minério, um metro cúbico de água, um hectare de terra fértil, etc.). Já há estudos mostrando ser possível quadruplicar a produtividade dos recursos naturais na medida em que se compreenda melhor o extraordinário desperdício de materiais e de energia 
no atual sistema industrial. Segundo o capitalismo natural, para corrigir as deficiências na operação das empresas, não basta atribuir valor ao capital natural, pois: a) muitos dos serviços que são recebidos dos sistemas vivos não têm substitutos conhecidos a qualquer preço; b) a avaliação do capital natural é um exercício difícil e quase sempre impreciso; c) da mesma forma que a tecnologia não pode substituir os sistemas que dão suporte à vida no Planeta, as máquinas também não têm condições de prover um substituto para a inteligência humana, o conhecimento, a sabedoria, as habilidades organizacionais e a cultura. O capitalismo natural propõe, também, um novo modelo industrial, no qual nem todos os produtos sejam apenas manufaturados e vendidos, mas que surja uma economia de serviços em que os consumidores adquirem serviços de bens duráveis por meio de aluguel e arrendamento, de tal forma que a indústria se responsabiliza pelo ciclo completo de materiais; deve lidar com os resíduos e os problemas resultantes de danos ambientais, toxicidade, segurança, etc.; recuperar os produtos e tratá-los como ativos; etc., o que termina por aumentar a produtividade dos materiais e da energia. Os provedores de serviços (de máquinas de lavar, de automóveis, de geladeiras, de televisores, de computadores, etc.) teriam um incentivo para manter seus ativos produtivos pelo maior tempo possível, em lugar de sucateá-los prematuramente a fim de vender substitutos de reposição e disporiam de economias de escala para a reciclagem de materiais residuais (Hawken, Lovin \& Lovin 2000; Hargreaves \& Smith 2005; Diamond 2005).

\section{Capitais intangíveis e desenvolvimento endógeno}

Muitos analistas dos problemas de regiões que acumularam um grande atraso econômico, ou que perderam seu dinamismo, estão convencidos que o desenvolvimento não se limita à expansão da capacidade produtiva (mais investimentos em projetos de infra-estrutura econômica ou em projetos diretamente produtivos). Celso Furtado ${ }^{5}$ (1982) afirma que o verdadeiro desenvolvimento é, principalmente, um processo de ativação e canalização de forças sociais, de melhoria da capacidade associativa, de exercício da iniciativa e da criatividade. Portanto, trata-se de um processo social e cultural, e apenas secundariamente econômico. O desenvolvimento ocorre quando, na sociedade, se manifesta uma energia capaz de canalizar, de forma convergente, forças que estavam latentes ou dispersas. Uma verdadeira política de desenvolvimento terá que ser a expressão das preocupações e das aspirações dos grupos sociais que tomam consciência de seus problemas e se empenham em resolvê-los.

Sergio Boisier tem insistido que o desenvolvimento de uma região ou localidade, no longo prazo, depende profundamente da sua capacidade de organização social e política para modelar o seu próprio futuro (processo de

${ }^{5}$ Ver também suas reflexões sobre o tema do desenvolvimento no livro da coleção "Os Economistas", publicado pela Abril Cultural: Teoria e Política de Desenvolvimento Econômico. Além disso, ver Franco, 2004. 
desenvolvimento endógeno), o que se relaciona, em última instância, com a disponibilidade de diferentes formas de capitais intangíveis na região ou localidade (ver Quadro 1).

QUADRO 1- FORMAS DE CAPITAIS INTANGÍVEIS DETERMINANTES DO PROCESSO DE DESENVOLVIMENTO REGIONAL

\begin{tabular}{|l|l|}
\hline $\begin{array}{l}\text { Algumas Formas de } \\
\text { Capitais Intangíveis }\end{array}$ & \multicolumn{1}{|c|}{ Especificação } \\
\hline 1. Capital Institucional & $\begin{array}{l}\text { As instituições ou organizações públicas e privadas existentes na } \\
\text { região: o seu número, o clima de relações interinstitucionais } \\
\text { (cooperação, conflito, neutralidade), o seu grau de modernidade. }\end{array}$ \\
\hline 2. Capital Humano & $\begin{array}{l}\text { O estoque de conhecimentos e habilidades que possuem os } \\
\text { indivíduos que residem na região e sua capacidade para exercitá- } \\
\text { los. }\end{array}$ \\
\hline 3. Capital Cívico & $\begin{array}{l}\text { A tradução de práticas de políticas democráticas, de confiança } \\
\text { nas instituições, de preocupação pessoal com os assuntos } \\
\text { públicos, de associatividade entre as esferas públicas e privadas, } \\
\text { etc. }\end{array}$ \\
\hline 4. Capital Social & $\begin{array}{l}\text { O que permite aos membros de uma comunidade confiar um no } \\
\text { outro e cooperar na formação de novos grupos ou em realizar } \\
\text { ações em comum. }\end{array}$ \\
\hline 5. Capital Sinergético & $\begin{array}{l}\text { Consiste na capacidade real ou latente de toda a comunidade } \\
\text { para articular de forma democrática as diversas formas de capital } \\
\text { intangível disponíveis nessa comunidade. }\end{array}$ \\
\hline
\end{tabular}

Fonte: Boisier ${ }^{6}, 2000$.

Percebe-se, com maior clareza, o conceito de desenvolvimento endógeno em situações de assimetria no retrocesso econômico. Por exemplo: se uma economia desenvolvida se atrofia ou involui por causa de um evento exógeno (por exemplo, países da Europa após a II Grande Guerra) e assume os indicadores de renda per capita, de comércio e de produtividade típicos de uma economia subdesenvolvida, quando recebe novos estímulos e incentivos (por exemplo, financiamentos e apoio técnico do Plano Marshall) a sua reação é rápida e acelerada, por causa de sua capacidade endógena de mobilizar capitais tangíveis e intangíveis para promover a retomada do desenvolvimento econômico e social.

Tradicionalmente, quando se deseja avaliar o grau de prosperidade de um país ou de uma região, utilizam-se indicadores de fluxos, tais como os fluxos de produção (PIB real per capita), os fluxos de consumo e de investimento, os fluxos de rendimentos (Renda real per capita), ocorridos durante um determinado período (geralmente um ano). Amartya Sen sugere que a prosperidade inclui, também, um diferenciado conjunto ou estoque de bens e

${ }^{6}$ Boisier menciona, ainda, como capitais intangíveis: o capital cultural, o capital cognitivo e o capital simbólico. 
ativos (capitais) que permitem melhorar os níveis de produtividade de uma região. Assim, mostra a vantagem de uma visão ou abordagem com as variáveis de estoque para se dar uma melhor idéia da capacidade de uma região produzir bens e serviços no futuro. Esta abordagem implica em que se dê aos sistemas de contabilidade social em termos de estoque, a mesma importância relativa que se dá atualmente, no Brasil, aos sistemas de contabilidade em termos de fluxos (agregados significativos, quadros de insumo-produto, fluxos financeiros).

Além da taxonomia proposta para os capitais intangíveis por Boisier, há várias classificações dos diversos tipos de capital que podem contribuir para o desenvolvimento de uma região. O Banco Mundial, por exemplo, distingue sete formas de capital (ver Diagrama 1), divididas em capital físico e capital social. Normalmente, as regiões menos desenvolvidas dispõem de uma concentração relativamente menor de capital social (ou intangível), justamente as formas de capital que dão sustentabilidade a um crescimento contínuo da produtividade e da prosperidade. 
DIAGRAMA 1- AS SETE FORMAS DE CAPITAL

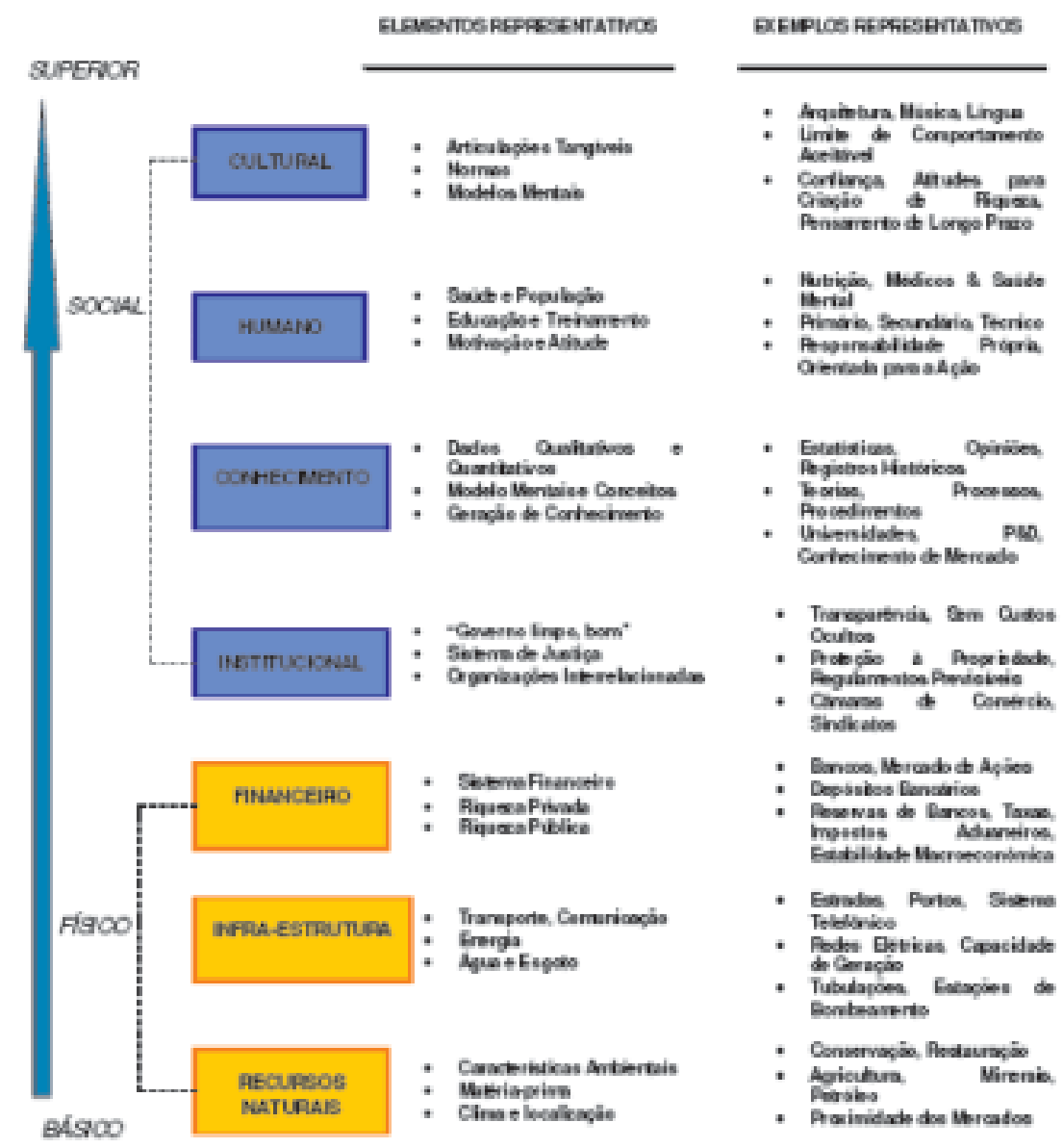

Fonte: Banco Mundial, 2001 
Particularmente, para muitas regiões menos desenvolvidas, a prosperidade de seus habitantes dependerá intensamente da qualidade da gestão do seu capital natural ou de seus recursos ambientais. Esta gestão tem ocorrido com maior freqüência, no Brasil, por meio de mecanismos institucionais de comando e controle, e com menor freqüência por meio de processos de gestão compartilhada (como por exemplo, por meio de comitês de gestão de recursos hídricos, envolvendo representantes da sociedade civil) ou por meio do uso de instrumentos econômicos de mercado (impostos, taxas, certificados negociáveis, etc.

Um processo de desenvolvimento endógeno é concebido e implementado a partir da capacidade que dispõe determinada comunidade para a mobilização social e política de recursos humanos, materiais e institucionais, em uma determinada localidade ou região. Um processo de desenvolvimento endógeno percorre, normalmente, algumas etapas (ver Diagrama 2):

- Não é um processo que brota no terreno do conformismo, da apatia, da inércia ou da passividade dos habitantes de uma região onde uma dinâmica de organização social e política ainda não se faz presente. Não há desenvolvimento onde não há inconformismo com relação ao mau desempenho dos indicadores econômicos, sociais e de sustentabilidade ambiental. Assim, numa primeira etapa, é importante organizar a estruturação deste inconformismo.

- A etapa seguinte tem sido procurar diagnosticar, técnica e politicamente, as razões e as causas do mau desempenho destes indicadores. Não se trata apenas de preparar documentos elaborados por especialistas mas, principalmente, de conscientizar as lideranças políticas e comunitárias sobre o que deve ser feito para transformar as condições atuais, visando a obter melhores índices de desenvolvimento humano, de competitividade econômica, etc.

- A terceira etapa envolve a transformação de uma agenda de mudanças em um plano de trabalho de mudanças (Plano de Ação). Um plano de trabalho que seja não somente tecnicamente consistente, mas essencialmente gerado a partir de uma intensa mobilização dos segmentos da sociedade civil, em regime de pacto e parceria com as autoridades e instituições locais e supra-locais. 
DIAGRAMA 2- ETAPAS DE UM PROCESSO DE DESENVOLVIMENTO ENDÓGENO

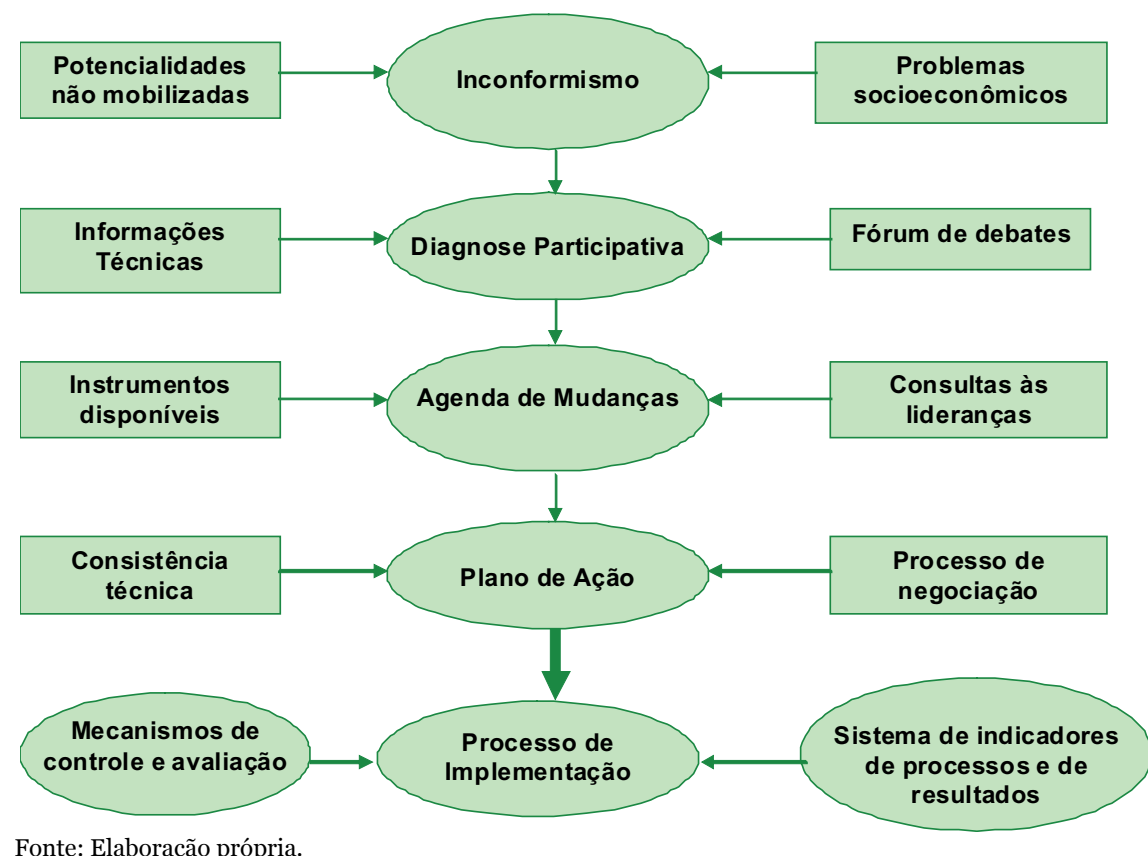

Fonte: Elaboração própria.

Usualmente, quando se entrevistam os principais líderes comunitários regionais ou locais, não é difícil diagnosticar que o seu inconformismo se encontra, muitas vezes, difuso ou latente, sem uma expressão formalizada ou explícita, quanto aos problemas econômicos, sociais e ambientais a serem resolvidos, ou quanto às potencialidades de crescimento econômico a serem mobilizadas. Para que possa haver um processo de mobilização social e política para o desenvolvimento de uma região subdesenvolvida, é importante, de início, conscientizar e sensibilizar as lideranças locais, explicitando e estruturando as características deste inconformismo latente e difuso.

A estruturação do inconformismo, em geral, envolve reflexões quanto ao baixo desempenho dos indicadores econômicos (taxa de crescimento do produto territorial, índice de valor agregado total, diversificação da base produtiva, adensamento da cadeia de valor econômico, etc.), dos indicadores sociais (taxa de analfabetismo, esperança de vida ao nascer, taxa combinada de matrículas e de frequência nos três níveis de ensino, concentração da renda e da riqueza, etc.) e dos indicadores de sustentabilidade ambiental (qualidade das microbacias hidrográficas, tratamento do lixo urbano, uso de defensivos agrícolas, etc.), como quanto ao reduzido nível de aproveitamento das oportunidades 
de investimentos disponíveis.

Entretanto, frustrações e anamneses podem ir se acumulando ao longo do tempo, durante anos e anos, sem que nada ocorra pela ausência de uma agenda ou um projeto estruturado de reformas e de mudanças. Um projeto que seja, não somente tecnicamente consistente, mas essencialmente gerado a partir de uma intensa mobilização dos segmentos organizados da sociedade civil em regime de pacto com as autoridades políticas locais ou regionais. Esta é a etapa mais difícil de se constituir, pois envolve um contexto específico de desenvolvimento político-institucional, o qual não se constata com maior freqüência entre as regiões e os municípios brasileiros, particularmente nas regiões menos desenvolvidas do País. Entretanto, em algumas microrregiões e municipalidades, a iniciativa de organizar esta etapa de ativação social e de romper com as inércias prevalecentes vem nascendo de lideranças empresariais, de lideranças políticas e tecnoburocráticas ou, também, de lideranças comunitárias locais.

Pode-se observar que, em geral, os projetos bem sucedidos de reformas e de mudanças nas cidades e nas regiões mais prósperas ocorreram em contextos que envolveram uma situação de expressiva endogenia no seu processo de desenvolvimento econômico e social. Ou seja, a forte presença de atores sociais (líderes políticos, empresariais, comunitários) na concepção e na condução das experiências de promoção do desenvolvimento, e não apenas o movimento de instituições e de agências externas ao município ou à região que atuam de forma excludente quanto à relativa autonomia decisória local. Neste sentido, a etapa de desenho e de execução de uma agenda de mudanças econômicas e sociais em uma área fica na dependência da qualidade de suas lideranças políticas e comunitárias: o seu nível de consciência social, de conhecimento sistêmico, de capacidade de gestão administrativa, de negociação em situações de conflitos e de tensões; a sua capacidade de atrair recursos de instituições e agências localizadas em seu entorno externo de decisão; etc.

Registra-se, também, em todos os casos de sucesso, alguma experiência de maior ou menor profundidade de reforma do setor público, envolvendo o ajuste fiscal e financeiro, uma reforma administrativa e, principalmente, uma especificação mais precisa dos limites e das articulações entre o espaço do setor público e o espaço do setor privado (Segundo Setor e Terceiro Setor). Quanto mais se definirem possibilidades de formas concretas de cooperação e de parceria entre estes dois setores, mais serão as chances de se superarem problemas econômicos e sociais e de se mobilizarem potencialidades de crescimento da economia local e regional. A identificação destas potencialidades e a sua ativação num contexto de competitividade dinâmica são a base indispensável para que uma economia urbana ou regional encontre uma trajetória de crescimento sustentado.

Neste sentido, não se pode esperar que a promoção do desenvolvimento econômico e social das regiões e dos municípios do País venha a ser realizada 
tão somente pelas instituições e agências do Governo Federal ou do Governo Estadual, as quais, na verdade, devem ser consideradas como parceiras potenciais na elaboração e na implementação de políticas, de programas e de projetos de mudanças concebidos e implementados a partir da atuação das sociedades locais.

\section{Educação superior e o conhecimento como fator de produção}

Nos primeiros modelos neoclássicos de crescimento econômico, o progresso tecnológico era considerado um elemento exógeno, não explicado dentro do próprio modelo; o progresso tecnológico era um dado do problema e explicado por fatores externos aos próprios modelos. Entretanto, as inovações não caem do céu. Ao contrário, são criadas pelos seres humanos, operando no intervalo normal de suas motivações, no processo de tentar resolver problemas de produção, de aprender a partir da experiência, de encontrar novas e melhores formas de fazer as coisas, de lucrar com a abertura de novos mercados. A inovação é, assim, um processo social (Aghion \& Howitt 1998).

O objetivo principal da teoria do crescimento endógeno é investigar e compreender a ação recíproca entre conhecimento tecnológico e várias características estruturais da economia e da sociedade, e quanto esta atuação recíproca resulta em crescimento econômico. $\mathrm{O}$ crescimento endógeno é o crescimento econômico gerado por fatores dentro do processo de produção (por exemplo: mudanças tecnológicas induzidas, rendimentos crescentes, economias de escala, etc.) em oposição a fatores externos (exógenos) tais como os acréscimos populacionais. Para Kaldor, desde que admitamos que rendimentos crescentes ocorram, as forças que promovem as mudanças contínuas são endógenas. Em termos da análise espacial, observa-se um renovado interesse pelas idéias de Alfred Marshall, que destacou os ganhos de eficiência decorrentes da aglomeração (clustering) de indústrias, a importância dos transbordamentos de conhecimento a partir da proximidade locacional, os rendimentos crescentes que resultam do conhecimento compartilhado, etc. Ele afirmava que:

São tais as vantagens que as pessoas que seguem uma mesma profissão especializada obtêm de uma vizinhança próxima, que, desde que uma indústria escolha uma localidade para se fixar, aí permanece por um longo espaço de tempo. Os segredos da profissão deixam de ser segredos, e, por assim dizer, ficam soltos no ar, de modo que as crianças absorvem inconscientemente grande número deles. Aprecia-se devidamente um trabalho de investimentos e discutem-se imediatamente os méritos de inventos e melhorias na maquinaria, nos métodos e na organização geral da empresa. Se um lança uma idéia nova, ela é imediatamente adotada por outros, que a combinam com sugestões próprias e, assim, essa idéia se torna uma fonte de outras idéias novas. Acabam por surgir, nas proximidades desse local, atividades subsidiárias que fornecem à indústria principal instrumentos e matérias-primas, organizam seu comércio e, por muitos meios, lhe proporcionam 
economia de material (Marshall 1982: 234).

Assim, as novas idéias que procuram explicar porque alguns países e regiões crescem e se desenvolvem mais rapidamente do que os demais, enfatizam o conhecimento como um fator de produção separado e a importância de investimentos na criação do conhecimento e nas atividades de Pesquisa e Desenvolvimento. Pessoas qualificadas são indispensáveis para descobrir novos conhecimentos, inventar novos produtos e novos processos tecnológicos, operar e manter equipamentos mais complexos, usar eficientemente novos produtos e novos processos, etc. O capital humano e as habilidades de um país ou região determinam o seu crescimento econômico no longo prazo e suas chances de transformar este crescimento em processos de desenvolvimento. Como as empresas tendem a subinvestir em Pesquisa e Desenvolvimento, onde os resultados são apenas parcialmente capturados e apropriados por elas, os governos nacionais e regionais deveriam tomar medidas apropriadas para superar esta falha de mercado. Com o processo de globalização econômica e financeira, tornou-se evidente que os diferenciais de competitividade entre países e regiões dependiam, em grande parte, da quantidade de recursos que cada Governo estava propenso a alocar em conhecimento e pesquisa e da eficácia de sua utilização (Tabb 1999; Velloso 2002; Gilpin 2001). Uma forma de ilustrar como a informação e o conhecimento, acumulados nas instituições de ensino superior, podem contribuir dinamicamente para o desenvolvimento regional, se apresenta nos processos de promoção de arranjos produtivos locais no Brasil, particularmente através do equilíbrio entre a oferta e a demanda de serviços de inovação.

Desde a abertura da economia brasileira no início dos anos 1990, o processo de globalização tem impactado diferentemente os setores produtivos e as economias regionais e urbanas do País. Para as grandes empresas que já estavam profundamente inseridas na economia global, os impactos foram de natureza incremental. Através de ajustes na margem em suas cadeias produtivas, conseguiram se adaptar ao novo ambiente macroeconômico de integração competitiva. Na verdade, estas empresas pertenciam a setores (celulose, mineração, agronegócios, alumínio, aço, etc.) que, na Segunda Divisão Internacional do Trabalho dos anos 1970, se consolidaram em países emergentes que se qualificassem com grande disponibilidade de fatores básicos (recursos naturais renováveis e não renováveis, energia, mão-de-obra abundante, fatores climáticos, etc.) e que foram igualmente complacentes, à época, com elevados índices de poluição ambiental gerada por estas atividades.

Muitas das empresas destes setores estavam sob o controle do Governo, e, após a privatização, obtiveram maior flexibilidade organizacional e capacidade competitiva. Basta ver os ganhos de eficiência microeconômica da CVRD e de empresas do setor siderúrgico, por exemplo, que, até então, se encontravam restringidas no seu desempenho econômico e financeiro pela crise fiscal do 
seu principal controlador, pela politização de seu processo decisório e pelas ambigüidades de sua missão institucional. Os indicadores econômicos e financeiros altamente favoráveis destas empresas são uma demonstração de que, quando destravadas das amarras da burocracia estatal, constituem um fator decisivo para o processo de competitividade global do País.

Por outro lado, as cadeias produtivas que tinham, em sua composição, uma empresa-âncora de maior escala, capaz de estruturar os interesses empresariais à jusante e à montante, conseguiram tornar-se competitivas globalmente em um período de tempo não muito longo e ampliaram as suas possibilidades de exportação. A empresa-âncora, neste tipo de situação, atuava como uma espécie de agência coordenadora das indispensáveis transformações produtivas e organizacionais em termos de tecnologia, marketing, engenharia financeira, etc. Na indústria automobilística e na indústria alimentícia, como ilustração, vislumbra-se esta ação coordenadora que viabilizou a competitividade sistêmica de um amplo conjunto de micro, pequenas e médias empresas (MPMEs) nas suas cadeias produtivas.

Entretanto, um número imenso de micro e pequenos empreendimentos, dispersos ou agrupados em diversos municípios e regiões do País, tiveram de enfrentar uma concorrência externa muito agressiva tendo, de um lado, todas as dificuldades típicas do Custo-Brasil (pesada carga tributária e previdenciária, custos financeiros e administrativos muito elevados, má qualidade da infra-estrutura econômica, etc.); e, do outro lado, competidores oriundos de economias estáveis com seus baixos custos financeiros, seus elevados padrões tecnológicos e suas modernas técnicas de gestão.

Para todas as MPMEs brasileiras, está valendo o esforço horizontal que vem sendo feito para modificar sua legislação tributária e para simplificar sua vida burocrática e administrativa, como foi o caso da recente aprovação do SIMPLES ampliado. Por outro lado, desde o início deste século, está em curso no País uma experiência focalizada de organizar os agrupamentos produtivos de MPMEs, espacialmente concentrados e especializados em negócios tradicionais (móveis, confecções, couro e sapatos, laticínios, granitos e cerâmica, etc.) e não-tradicionais (cultura, tecnologia de informação, turismo sustentável, etc.) sob a forma de arranjos produtivos locais.

Um arranjo produtivo local se define como uma concentração microespacial de empresas que trabalham, direta e indiretamente, para o mesmo mercado final, que compartilham de valores e conhecimentos tão importantes que definem um ambiente cultural, e que são especificamente interligadas num mix de cooperação e de competição. A principal fonte de competitividade são os elementos de confiança, de solidariedade e de cooperação entre empresas, assim como a existência de uma estrutura de apoio institucional, compreendendo instituições do setor público e do setor privado (agentes financeiros, universidades, instituições de pesquisa, centros tecnológicos, serviços de apoio especializado, etc.). 
Há, atualmente, em diferentes setores produtivos e regiões do País, quase trezentas experiências de promover e desenvolver agrupamentos localizados de MPMEs, quase todas com intensa participação do SISTEMA SEBRAE, das quais algumas já se qualificam como arranjos produtivos locais pelas suas características estruturais mais avançadas.

São experiências de parcerias público-privado que aproveitam as lições históricas dos distritos industriais da Terceira Itália; com modelos de governança de auto-gestão empresarial; que exploram os benefícios de cooperar para competir pelo uso eficiente e eficaz de instrumentos econômicos e mecanismos institucionais já disponíveis; onde se procura resolver problemas comuns a grupos de micro e pequenos produtores que isoladamente não teriam como resolvê-los (logística, inovações tecnológicas, inteligência comercial, infraestrutura especializada, etc.).

Sem este esforço de conceber e implementar estratégias competitivas para os agrupamentos de MPEs, pode-se pensar, num caminho seqüencial de darwinismo econômico: amplia-se o grau de abertura econômica; há um novo choque competitivo com a liberação do comércio para gigantes da economia mundial (Estados Unidos, Canadá, União Européia, China, Japão), até mesmo em mercados de produtos tradicionais; e o mercado acaba preservando apenas os agrupamentos produtivos nacionais que apresentarem maior grau de adaptabilidade ao novo ambiente econômico. Caracteriza-se, assim, um quadro de reprodução das assimetrias e das desigualdades de oportunidades entre os diferentes segmentos produtivos do País.

Além da experiência dos distritos industriais da denominada Terceira Itália, há outros casos de sucesso de promoção e desenvolvimento de aglomerações produtivas tais como os clusters nos Estados Unidos, onde se destaca o Vale do Silício, as redes de empresas no Japão, Coréia e Taiwan, os sistemas produtivos locais na França, Alemanha e Reino Unido, etc. (Moreira, AMorim \& Ipiranga 2006)7. Paolo Gurissati chega a descrever a economia de uma macrorregião européia denominada Área de Desenvolvimento do Arco Alpino (Nordeste da Itália, Rhône-Alpes na França, Baden Württenbery e Baviera na Alemanha, Suíça e Áustria) com indicadores econômicos extremamente favoráveis, onde as MPMEs continuam a ser a principal fonte de crescimento do emprego e dos investimentos em quase todos os setores da economia regional. A experiência inovadora do Nordeste da Itália ("A Terceira Itália") se deu a partir dos anos 1970, quando ainda eram muito graves as inconsistências macroeconômicas no país (Gurissati 1999).

No Projeto Cresce Minas do Sistema FIEMG, buscou-se distinguir, do ponto de vista estritamente econômico, o APL de outras aglomerações produtivas/

${ }^{7}$ Neste trabalho, as autoras distinguem os APLs dos sistemas produtivos locais que apresentam níveis mais elevados de organização interna e são definidos como "arranjos produtivos cuja interdependência, articulação e vínculos consistentes resultam em interação, cooperação e aprendizagem, possibilitando inovações de produtos, processos e formatos organizacionais e gerando mais competitividade empresarial e capacitação social." 
pólos econômicos, como ilustrado no Diagrama 3

DIAGRAMA 3 - APL: DISTINÇÃO DE OUTRAS AGLOMERAÇÕES PRODUTIVAS

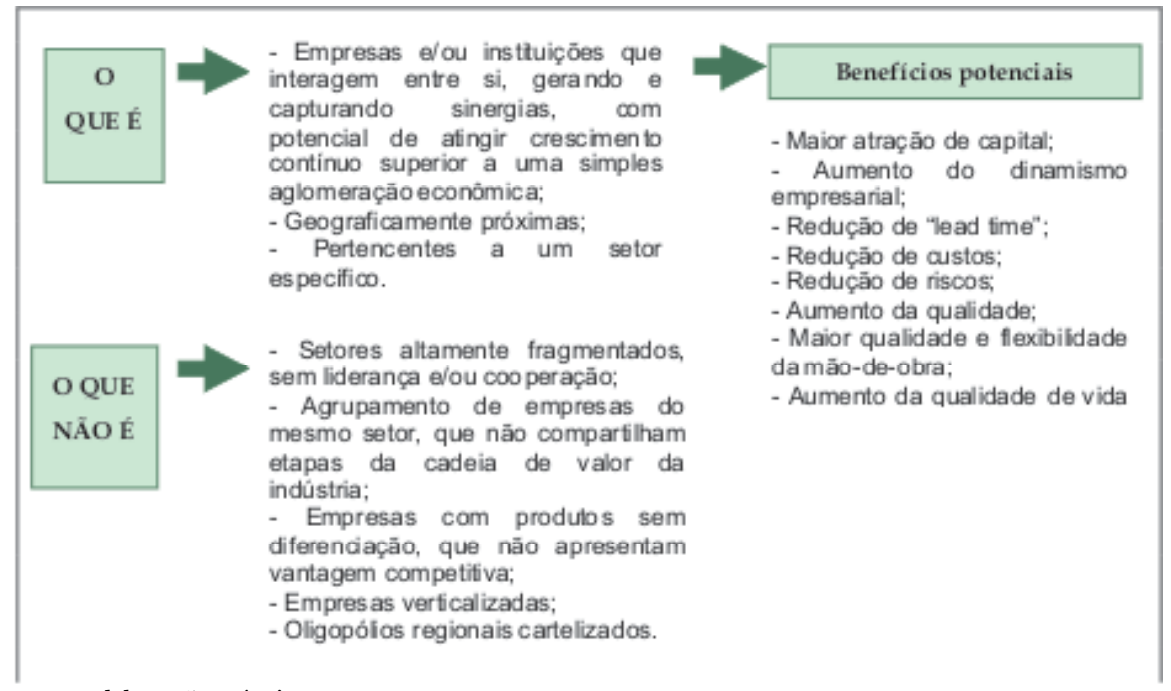

Fonte: Elaboração própria.

Em resumo: existe um conjunto de características que, quando presentes em uma atividade econômica, potencializam os benefícios de eficiência coletiva, de aprendizado conjunto e de inovação, gerados pelas economias dinâmicas de aglomeração (Porter 1993; 1998)

- Dimensão territorial delimitada: A proximidade geográfica leva ao compartilhamento de visões e valores econômicos, como mão-de-obra especializada, fornecedores e principalmente conhecimento tácito, aquele que não está codificado, mas está implícito e incorporado nos indivíduos.

- Diversidade de atores econômicos, políticos e sociais: A presença de diferentes instituições estimula a inovação, pois favorece a formação e a capacitação da mão-de-obra, o investimento em pesquisa, o desenvolvimento e o acesso a fontes de capital.

- Governança / coordenação: A maneira como os diferentes atores coordenam suas atividades e investimentos favorece a criação de economias de escala antes inexistentes, como compras conjuntas, investimentos compartilhados em P\&D e treinamento, compartilhamento de infra-estrutura de logística, etc.

\footnotetext{
${ }^{8} \mathrm{O}$ conceito de APL não se confunde com o conceito de pólo de desenvolvimento (associado, geralmente, a um grande projeto de investimento geograficamente localizado e que mantém fortes vínculos com suas áreas de influência política, social, econômica e institucional; pólos são as indústrias motrizes ou propulsivas, atores dominantes no crescimento das regiões e localidades), nem com o conceito de complexo industrial (um conjunto de atividades que ocorrem numa dada localização e pertencem a um grupo ou subsistema, sujeitas a importantes interrelações de produção, comercialização e tecnologia).
} 
- Vocação e/ou Relevância da Atividade Econômica: Quando uma atividade é relevante para a região, seja pela importância para a economia local, seja por uma vocação da região, a mobilização da população e das instituições de apoio é muito mais provável.

No estudo realizado pelo Consórcio Monitor-Boucinhas/Campos para o Projeto de Atualização dos Eixos Nacionais de Integração e Desenvolvimento, foram identificados oito arquétipos de aglomerações ou agrupamentos produtivos no Brasil, os quais apresentam características estruturais (nível de organização e confiança, processos tecnológicos, condições de fatores, etc.) que levam a políticas públicas diferenciadas para a sua promoção e seu desenvolvimento.

- Agrupamento de Sobrevivência Informal

Dentro desse contexto, a atividade econômica é preponderantemente informal, representada por grupos de pequenos produtores autônomos ou por grupos familiares; exploram a vantagem comparativa da existência de fatores básicos ou não-especializados da região para a sobrevivência, de maneira muito precária; exemplos: meleiros, artesanato, extrativismo, etc.

\section{- Agrupamento de Vantagem Comparativa}

Normalmente, apresenta-se como um agrupamento de micros, pequenas e médias empresas, muitas das vezes empresas informais que agregam reduzido valor aos fatores básicos da região, quase sempre atuando como produtores de manufatura de primeiro beneficiamento; exemplos: gesso- Serra do Araripe (PE), fruticultura irrigada- Mossoró - (RN), etc.

- Agrupamento Modelo Tradicional de Crescimento

Grupo formado por pequenas e médias empresas que, muitas vezes, convivem com algumas empresas de grande porte, mas com pouco relacionamento entre elas; apesar de já agregarem valor ao produto e ocuparem posições importantes no mercado regional ou nacional, falta visão estratégica de crescimento sustentável; exemplos: moda íntima - Nova Friburgo (RJ), coureiro-calçadista - Campina Grande (PB), etc.

\section{- Agrupamento de Alavancagem Competitiva}

Nesse contexto, as micros e pequenas empresas convivem com grupo de empresas de grande porte, atuando em diversas etapas da cadeia produtiva; dentre elas, existem empresas que se destacam no mercado nacional, mas que encontram dificuldades estratégicas para competir no mercado internacional; exemplos: coureiro-calçadista-Vale dos Sinos (RS); cerâmica - Criciúma (SC); têxtil- Itajaí (SC); moveleiro- Serra Gaúcha (RS), etc.

\section{- Agrupamento Baseado em Empresa-âncora}

É um conjunto de pequenas e médias empresas que fornecem produtos/ serviços para uma ou mais grandes empresas (âncora), geralmente empresas nacionais; a cooperação vertical é forte entre as empresas-âncora e as empresas fornecedoras; há aqui o objetivo de promover o desenvolvimento da cadeia produtiva como um todo; exemplos: metal-mecânico no Espírito Santo, 
suinícola do Oeste de Santa Catarina; petrolífero no Rio de Janeiro, etc.

- Agrupamento Dependente de Logística Exportadora

É formado por empresas de médio e de grande porte que, geralmente, possuem competitividade produtiva mundial, resultado de condições naturais propícias e de desenvolvimento tecnológico; essas empresas são fortemente dependentes de logística eficiente e competitiva internacionalmente; entretanto, possuem presença internacional aquém do seu potencial; exemplos: fruticultura - Juazeiro (BA) e Petrolina (PE); soja - Barreiras (BA); proteína animal - Triângulo Mineiro (MG), etc.

- Agrupamento de Base Tecnológica

É formado, preponderantemente, por grupo de micros, pequenas e médias empresas, normalmente spin-offs das universidades locais/incubadoras; geralmente, elas convivem com empresas maiores e competem em setores intensivos em tecnologia; entretanto, apesar do grande conhecimento tecnológico existente, essas MPMEs ainda não possuem posicionamento consolidado no mercado nacional e no mercado internacional; exemplos: base tecnológica - São Carlos (SP); software - Joinville (SC); biotecnologia da Região Metropolitana de $\mathrm{BH}(\mathrm{MG})$, etc.

\section{- Agrupamento de Alta Tecnologia}

Uma empresa-âncora (ou mais) estrutura uma cadeia produtiva global (apoiada por micros, pequenas e médias empresas de alta tecnologia) para elaborar produto (ou produtos) de alta complexidade, atendendo tanto o mercado interno como demandas globais; em alguns casos, essas empresas destacam-se no mercado internacional como "plantas produtivas", a partir de estratégias da empresa matriz; exemplos: automotivo - Belo Horizonte; telecomunicações - Campinas (SP); aeronáutica - São José dos Campos (SP), etc.

A questão da inovação emerge em todos os diferentes agrupamentos, independentemente de seu nível de desenvolvimento e organização. É tão importante definir o uso alternativo do caranguejo (a sua casca como cicatrizante, por exemplo) no Delta do Parnaíba (MA e PI) ou do babaçu (o seu endocarpo ou mesocarpo como fármaco ou insumo energético, por exemplo) no Centro-Leste do Maranhão, atividades tipicamente extrativistas, quanto um novo produto em um agrupamento produtivo de biotecnologia ou de software.

Michael Porter tem destacado, em seus estudos sobre a vantagem competitiva, que os países e regiões, que estruturam as suas economias na produção de bens e serviços intensivos em fatores básicos (recursos naturais, mão-de-obra qualificada ou semi-qualificada, fatores climáticos, etc.), são incapazes de gerar os fundamentos de uma competitividade sustentável, assim como prover de melhores condições de vida os habitantes; as economias destes países e regiões se caracterizam por:

- apresentam um ciclo vicioso da destruição da riqueza;

- sofrem, com frequência, um processo de deterioração nas suas relações de troca; 
- se destacam pelos valores baixos de seus indicadores sociais;

- vêem se ampliar o número de seus concorrentes em escala global, dadas as facilidades de entrada no mercado daqueles bens e serviços;

- não têm condições de sustentar o seu processo de crescimento no longo prazo.

Infelizmente, esta é a situação da grande maioria das economias urbanas e sub-regionais do País e, particularmente, das suas áreas menos desenvolvidas, as quais necessitam, urgentemente, de serem reestruturadas, antes que ocorra um novo choque de integração competitiva a partir da concorrência avassaladora da China e da Índia ou da formação da ALCA nos próximos anos, fragilizando-as ainda mais 9 .

Assim, é preciso identificar, de forma sistemática, o conjunto de chances, ameaças e riscos que envolvem a dinâmica e a sustentabilidade dos APLs que se baseiam em vantagens comparativas, mapeando pontos de estrangulamento e oportunidades perdidas, levando os principais atores do APL a um comportamento pró-ativo de maior cooperação e integração dos interesses locais. Entre estes riscos e ameaças, destacam-se:

- mesmo que, no curto prazo, ainda haja atividades dentro do APL que estão apresentando níveis razoáveis de rentabilidade financeira, a médio e a longo prazo esta rentabilidade pode estar ameaçada pelas fáceis condições de entrada de novos concorrentes, expandindo a oferta e deprimindo as margens de lucro;

- a replicabilidade de APLs equivalentes é tanto maior quanto mais os fundamentos do APL específico estiverem alicerçados sobre fatores básicos (clima, recursos naturais renováveis e não-renováveis, mão-de-obra abundante, etc.);

- o processo de abertura da economia brasileira é irreversível a longo prazo e as suas implicações (redução dos impostos de importação, desregulamentação do comércio exterior, etc.) devem provocar um novo choque competitivo para as empresas que compõem o APL, tornando indispensável um processo de

${ }^{9}$ É preciso reconsiderar múltiplos aspectos dos impactos do processo de globalização econômica e financeira sobre as economias nacionais e regionais que têm, por base de crescimento, a exploração de seus recursos naturais. A complexidade da demanda global por certas especificações de qualidade dos produtos de origem primária (zoosanidade, fitosanidade, manejo sustentável, logística, certificação, etc.) leva a que estes produtos tenham maior intensidade de capitais intangíveis (humano, conhecimento tecnológico, institucional, etc.) do que um grande número de produtos industrializados tradicionais, reproduzidos em regime de economia informal. Ou seja, os produtos primários, que chegam na ponta da demanda final, carregam um elevado conteúdo de fatores especializados do tipo man-made. Além do mais, mesmo que por unidade do PIB haja uma menor intensidade de recursos naturais nas economias modernas, por razões de melhorias de produtividade e da existência de novos materiais, tende a crescer o volume da demanda global por bens e serviços direta e indiretamente relacionados com a base de recursos naturais. Este crescimento pode ocorrer de forma acelerada e sustentada, a partir de expressiva entrada de países como a China e a Índia no mercado mundial de bens e serviços; da persistência do longo ciclo de prosperidade nos países industrializados; da melhoria da distribuição da renda em muitos países em desenvolvimento. Neste caso, mesmo considerando a ocorrência de alguns anos de volatilidade nos seus mercados, com implicações adversas em seus preços relativos no curto prazo, é possível pensar até na atenuação da tradicional tendência de uma deterioração nas relações de troca destes bens e serviços, ao longo do próximo lustro. 
melhorias nas suas condições de competitividade;

- por meio de inovações tecnológicas, os países industrializados estão conseguindo aumentar suas possibilidades de substituição dos produtos intensivos em fatores básicos (fibras sintéticas versus fibras naturais; novos materiais versus materiais tradicionais; etc.), encolhendo ainda mais os mercados destes produtos tradicionais que constituem a base dos APLs;

- por meio de novas técnicas de gestão e de novos processos produtivos, é crescente a economia de insumos e fatores básicos (redução nos coeficientes técnicos de produção) nos processos de transformação industrial mais avançada.

À medida que vão se construindo e alavancando as vantagens competitivas de um APL, num contexto em que a cultura local favorece o associativismo e sistemas de crenças que contribuem para melhor gerar e distribuir a riqueza, vão sendo colhidos os benefícios das economias de aglomeração (Fujita \& Thisse 2002; Cassiolato \& Lastres 2001; Haddad 2002; Sebrae, Promos \& Bid 2004). Em Estudo recente da Fundação Getúlio Vargas para o SEBRAE/RJ e a FIRJAN, destacam-se as vantagens competitivas, analisadas por Michael Porter e relacionadas às organizações produtivas aglomerativas em APL:

- Maior eficiência na contratação da mão-de-obra e relação com fornecedores: no que se refere à mão-de-obra, a existência de um pool de profissionais especializados e experientes reduz os custos de recrutamento; quanto aos fornecedores, é natural que o APL passe a receber atenção especial dos mesmos, formando uma base sólida e especializada;

- Acesso a informações especializadas: os APLs acumulam uma grande quantidade de informaçõ̃es dos mais diversos tipos, com acesso preferencial garantido a seus membros; além disso, os relacionamentos pessoais e os laços com a comunidade promovem a confiança e facilitam os fluxos de informações;

- Externalidades positivas: a organização em APLs gera uma série de externalidades positivas, relacionadas, por exemplo, ao marketing dos produtos e à redução do custo de procura dos clientes, que encontram uma diversidade de alternativas no âmbito do próprio APL;

- Acesso a instituições e bens públicos: o APL favorece o acesso a bens públicos fornecidos pelo governo; além disso, nos APLs, muitos investimentos privados em infra-estrutura, centros de qualidade, laboratórios de teste, etc., são realizados coletivamente;

- Melhor motivação e avaliação do desempenho: a concorrência local é considerada motivadora, e a organização em APLs permite um permanente processo de comparação de desempenho, uma vez que os concorrentes locais estão expostos às mesmas condições;

- Inovação: além do acesso direto aos clientes mais sofisticados, o relacionamento permanente com outras entidades contribui para que as empresas saibam, com antecedência, como a tecnologia está evoluindo, qual a disponibilidade de componentes e máquinas, quais os novos conceitos de serviços e marketing, etc. 
As atividades econômicas para se tornarem globalmente competitivas, particularmente quando se trata das MPMEs, dependem de sua eficiência operacional e de seu posicionamento estratégico. Para alcançar maiores ganhos, é necessário servir segmentos atrativos de mercado; esses novos segmentos requerem diferentes capacidades e exigem que se aumente a eficiência operacional (Fairbanks \& Lindsay 1997; Porter 1993; Haddad 2003). Entre as estratégias competitivas selecionadas, destacam-se:

- estratégia de diferenciação de produto: corresponde à introdução na linha de produtos das firmas de uma nova mercadoria que é substituta próxima de alguma outra previamente produzida e que, portanto, será vendida em um dos mercados supridos pelas firmas; esta nova mercadoria pode surgir da melhoria de qualidade ou de modificações nas especificações; estratégias de diferenciação podem se basear no nome da marca, em design, tecnologia, serviços ou outras dimensões requeridas pelos consumidores mais exigentes, os quais estão dispostos a pagar mais por um valor que percebem nos produtos; exemplo: a introdução de um novo cultivar em um APL de frutas tropicais que apresente características (sabor, transportabilidade, etc.) mais adequadas às preferências dos consumidores;

- estratégia de diversificação: corresponde à introdução, nas linhas de produtos das firmas de uma mercadoria a ser vendida em um mercado do qual não participavam até então; as firmas se movem para além do seu mercado corrente através da realização de investimentos em uma nova indústria ou setor, em busca de maiores valores agregados; exemplo: produtores de óleo e farelo de soja que investem em produtos de proteína de soja (antibióticos, cosméticos, produtos alimentícios dietéticos, etc.);

- estratégia de custos baixos: a competitividade baseada em custos baixos não é, geralmente, sustentável e se fundamenta em componentes aleatórios (câmbio desvalorizado), espúrios (economia informal) ou predatórios (uso insustentável da base de recursos naturais renováveis e não-renováveis); estratégias de baixos custos são sustentáveis quando baseadas em inovações duradouras (novos processos, logística, etc.).

Em princípio, não se pode dizer que haja uma escolha de estratégia competitiva melhor do que outra. As empresas localizadas ou a se localizarem nos APLs devem fazer uma cuidadosa avaliação de seu ambiente competitivo e da estrutura industrial para definir qual abordagem estratégica é mais viável e sustentável. A escolha de uma nova tecnologia, por exemplo, somente é desejável para uma empresa, se cria uma vantagem competitiva sustentável, desloca custos a seu favor, traz vantagens de pioneirismo ou melhora o conjunto da estrutura industrial. As circunstâncias de cada contexto acabam tendo um peso significativo em cada escolha e delimitam quais funções programáticas devem ser priorizadas nos planos de ação dos APLs. Em qualquer circunstância, contudo, será indispensável que haja uma oferta flexível e dinâmica de serviços de inovação para se conquistarem novos produtos, novos processos, novos mercados ou novas técnicas de gestão, onde as instituições de ensino superior têm um papel particularmente diferenciado a desempenhar no processo de desenvolvimento regional. 


\section{Referências}

AGHION, P. \& HOWITT, P. (1998). Endogenous Growth Theory. New York: The MIT Press.

ANAND, S. \& SEN, A. (1996). Sustainable Human Development: Concepts and Priorities. New York: UNDP.

BANCO MUNDIAL (2001). Relatório sobre o Desenvolvimento Mundial. Washinton, D.C.: The World Bank.

BOISIER, S. (1992). El Dificil Arte de Hacer Región. Cusco: Centro de Estudios Regionales Andinos.

BOISIER, S. (2000). Conversaciones Sociales Y Desarrollo Regional. Talca: Editorial de la Universidad de Talca.

CASSIOLATO, J. \& LASTRES, H. (2001). “Aglomerações, Cadeias e Sistemas Produtivos e de Inovação”. Revista Brasileira de Competitividade; 1(1, abril/julho).

CEPAL (1992). Equidad y Transformación Productiva: Um Enfoque Integrado. Santiago: CEPAL.

DIAMOND, J. (2005). Collapse - How Societies Choose to Fail or Succeed. New York: Viking.

FAIRBANKS, M.; LINDSAY, S. (1997). Plowing The Sea - Nurturing the Hidden Sources of Growth in the Developing World. New York: HBS Press.

FRANCO, A. (2004). Capital Social. Brasília: Instituto de Política Millennium.

FUJITA, M. \& THISSE, J. F. (2002). Economics of Agglomeration: Cities, Industrial Location and Regional Growth. London: Cambridge University Press.

FURTADO, C. (1982). A Nova Dependência. São Paulo: Paz e Terra.

GILPIN, R. (2001). Global Political Economy: Understanding the International Economic Order. Princeton: Princeton University Press.

GURISSATI, P. (1999). "O Nordeste Italiano: Nascimento de um Novo Modelo de Organização Industrial”. In: COCCO, G.; URANI, A.; GALVÃO, A. (orgs). Empresários e Empregos nos Novos Territórios Produtivos: O Caso da Terceira Itália. São Paulo: DPA Editora.

HADDAD, P. (2002). "Etapas de Organização de um Cluster Produtivo: uma exposição diagramática”. Revista Brasileira de Competitividade, 2 (1, abril/julho).

HADDAD, P. (2003). "Tendências Recentes do Comércio Internacional e suas Implicações para a Economia de Minas”. Cadernos BDMG, abril.

HADDAD, P. \& REZENDE, F. (2002). Instrumentos Econômicos para o Desenvolvimento Sustentável da Amazônia. Brasília: MMA/SCA.

HARGREAVES, K. \& SMITH, M. (2005). The Natural Advantage of Nations. London: Earthscan.

HAWKEN, P. \& LOVINS, A. \& LOVINS, L. H. (2000). Natural Capitalism: Creating the Next Industrial Revolution. Boston: Little, Brown and Company. 
HADDAD, P. R. Capitais Intangíveis e desenvolvimento...

KOLSTAD, C. K. (2000). Environmental Economics. London: Oxford University Press.

LEVY, P. \& VILLELA, R. (2006). Uma Agenda para o Crescimento Econômico e a Redução da Pobreza. IPEA, Texto para discussão n. 1234.

MARSHALL, A. (1982). Princípios de Economia Política. Coleção Os Economistas, vol. 1, São Paulo: Abril Cultural.

MIN (1995). Projeto Áridas: uma estratégia de desenvolvimento sustentável para o Nordeste. Brasília: MIN.

MMA (2002). Agenda 21 Brasileira. Brasília: MMA.

MOREIRA, M. \& AMORIM, M. \& IPIRANGA, A. (2004). "Um modelo de tecnologia social de mobilização para arranjos produtivos locais: uma proposta de aplicabilidade", EnANPAD, Curitiba.

PEARCE, D. \& TURNER, R. (1991). Economics of Natural Resources and the Environment. Baltimore, Maryland: Johns Hopkins.

PORTER, M. E. (1993). A Vantagem Competitiva das Nações. São Paulo: Campus.

PORTER, M. E. (1998). "Clusters and the New Economics of Competition”. Harvard Business Review Nov./dec.: 77-90.

ROCHA, S. (2003). Pobreza no Brasil: Afinal de que se trata? Rio de Janeiro: FGV Editora.

ROCHA, S. (2006). "Pobreza e Indigência no Brasil - Algumas evidências com base no PNAD 2004". Nova Economia, 16(2).

SCHWARTZMAN, S. (2004). Pobreza, Exclusão Social e Modernidade: uma introdução ao mundo contemporâneo. São Paulo: Augurium Editora.

SEBRAE/PROMOS/BID (2004). Metodologia de Desenvolvimento de Arranjos Produtivos Locais. São Paulo: SEBRAE.

SEN, A. (2000). Development as Freedom. New York: Anchor Books.

TABB, W. K. (1999). Reconstructing Political Economy: the great divide in economic thought. London: Routledge.

VELlOSO, J. P. R. (org.) (2002). Brasil e a Economia do Conhecimento. Rio de Janeiro: José Olympio Editora.

Recebido em: 01 de abril de 2008. Primeira resposta em: 29 de abril de 2008. Aceite em: 20 de fevereiro de 2009. 